ORIGINAL ARTICLE

\section{Poverty Reduction Strategy Papers and their contribution to health: An Analysis of Three Countries}

Sam Bartlett

ABSTRACT: Poverty Reduction Strategy Papers (PRSPs) represent the World Bank and the International Monetary Fund's (IMF) most recent initiative for reducing the plight of the poor. This paper examines whether the PRSPs for Liberia, Afghanistan and Haiti follow World Bank guidance on health. The health data, analysis and strategy content of the three PRSPs are assessed with respect to the 'Health, Nutrition and Population' chapter of the World Bank's PRSP Sourcebook. This guidance states that PRSPs should include: health data on the poor and a clear analysis showing the determinants of ill health and pro-poor health strategies. Unfortunately, none of the PRSPs analysed comply with the guidance and, consequently, do not adequately portray the health situation within their countries. Thus health is not given a high priority in the PRSP process and is seemingly low on the agenda of both poor country governments and the International Financial Institutions (IFIs). If the situation for the world's poorest people is to improve, health and the right to health need to be promoted within PRSPs.

Keywords: World Health, Developing Countries, International Cooperation, Internationa Agencies, Poverty, Health Policy

INTRODUCTION

The relationship between poverty and health has been widely reported. Moreover, extreme poverty is classified as a disease in itself (1). More than one billion people worldwide live in extreme poverty, which equates to an equivalent income of less than $\$ 1.25$ per person per day at purchasing power parity. Reducing poverty is an international priority and is the focus of the Millennium Development Goal 1.

The World Bank and the International Monetary Fund (IMF) are United Nations

*To whom correspondence should be addressed:

Sniversity of Bristol, Faculty of Medicine organisations. They are International Financial Institutions (IFIs) that are involved in global development, providing countries with technical, operational, and financial assistance. Poverty Reduction Strategy Papers (PRSPs) represent their most recent initiative for reducing the plight of the poor

This paper seeks to assess whether the health content of three PRSPs, Liberia, Afghanistan and Haiti, follow the guidance provided by the World Bank. Specifically, the PRSPs are examined with respect to Chapter 18 of the World Bank's Sourcebook entitled 'Health, Nutrition and Bank's Sourcebook entitled 'Health, Nutrition and Population' (from now on HNP Sourcebook) (2) concerning
strategies.

\section{A BACKGROUND TO PRSPS}

PRSPs are documents written every three years by governments of less economically developed countries (LEDCs) and are intended to "describe a country's macroeconomic, structural and social policies and programs to promote growth and reduce poverty, as well as associated external financing needs" (3). PRSPs promote 'national ownership' and place poverty reduction at centre stage (4). Governments can produce an interim PRSP (iPRSP) before developing a full PRSP, enabling them to qualify for partial debt relief without having to wait until a full PRSP is prepared (5). The World Bank and IMF analyse a country's PRSP and write a Joint Staff Assessment Note (JSAN). Countries require positive JSAN feedback to receive debt relief (6). In addition to debt relief, to receive debt res the main mechanism for relief, PRSPs represe (6) and foreign aid (7).

There are fears that countries develop PRSPs with a rushed approach, which are biased in favour of donor wishes, in order to receive much needed financial aid $(5,6)$. In addition, even though the countries preparing PRSPs have different economic climates, resources, and governments, PRSPs have resulted in very similar economic policies. The homogenous nature of economic policies given in PRSPs, suggests that IFIs are influencing LEDC governments and thus that there is a lack of country-ownership (8).

Both iPRSPs and PRSPs have been criticised for their inadequate health content. For example, Laterveer et al. (9) found few iPRSPs gave disaggregated health data for income and most did not identify the major causes of illness amongst poor populations. In one study, six of twent-one PRSPs gave no disaggregated health data at all (10). This results in the PRSPs that do not discuss the inequalities in health between the rich and the poor and thus, this questions their poverty focus. Major causes of illness were identified but with scant evidence and analysis (10). In addition, there is a lack of analysis on why (10). In aw health systems are faling the poor (10). Niger and Mozambique, for examp poor (10). Niger and Mozambique, for example, provided disaggregated health data by distict and yet the inequalties identied were not addressed in their difficult to determine whether health strategies outlined in PRSPs are new and due to the PRSP process or are from existing health strategies (5 ). It may be that governments simply 'copy and aste' existing health policies into PRSPs, possibly in an attempt to complete the PRSP as quickly as possible.

Whilst PRSPs seemingly approach health from a developmental perspective, as a tool for increasing human capital and economic growth none address health as a human right $(1,6,10)$. The right to health is enshrined in various human rights documents like Article 12 of the UN Internationa Covenant on Economic, Social and Cultural Rights (ICESCR) (11) and within the constitution of the World Health Organisation (WHO). Furthermore every State has an obligation to work towards a global realisation of this right.

METHODS

All PRSPs available on the World Bank website were included in the selection process. Countries which submitted PRSPs from 2005 onwards were first selected. It is clear that countries with multiple PRSPs tended to include much more health data in the first PRSP than the subsequen papers. Therefore, this analysis was confined to country's first PRSP. Thirteen PRSPs met these inclusion criteria and, in order to facilitate a detailed analysis, three PRSPs were selected at random from different continents. Wider determinants of health such as water, sanitation, housing and education are, in practice, intractable from this discussion, however are addressed outside of the HNP Sourcebook. In addition, although the HNP Sourcebook discusses nutrition, PRSPs commonly discuss it separately from health. Therefore, to maintain consistency and clarity, these factors are not discussed at length

THE WORLD BANK'S SOURCEBOOK

The World Bank defines the Sourcebook as a framework and not a blueprint, emphasising that it is not mandatory for countries to rigidly follow it (12) . The HNP Sourcebook brifly discusso the relationship between poverty and health chequich subsequenty addressing the key stages in policy design, diagnostics and analysis, government (2). A sur (2). A summary of the recommendations made by
HNP Sourcebook is given in Figure 1. 


\section{PRSPs should include ${ }^{\varnothing:}$}

- The main health outcomes for the population

- Disaggregated health data for income groups

- Disaggregated health data for geographic locations

- Analysis of health outcomes based on household, community and

\section{health system factors}

- Understanding of the underlying causes of health outcomes

- Health strategies which reflect the needs of the poor

- Health strategies which aim to increase equity within the health system

\section{Figure 1: The main recommendations made by the HNP Sourcebook. Note: Examples of household factors are: household} income and knowledge of health services. Examples of community factors are: cultural norms and cont
Examples of health service factors are: accessibility of services and human resources within services.

\section{THREE PRSPS: AN ANALYSIS}

All three countries in this analysis (Liberia, damaged infrastuctures and dilapidated public services. Thus, they face considerable difficulties in collecting health data and subsequently developing health policy.

Data data and disaggregated data is missing despite the HNP Sourcebook emphasising its importance. Consequently, the health situation within the countries, the extent of health inequalities, and gave the infant mortality rate (IMR) as 72 deaths down by population group. Prior to the PRSP, the down by popul the Howp. Pil did not break the Govern Health Suney (DHS) (13) which showed that the IMR was higher for poorer households, yet this evidence was not included in the PRSP. Similarly, in Afghanistan, maternal mortally rates have been shown to vary between disticts and are fifteen times higher in Ragh (rural) than Kabul (urban) (14), Without such data, it is difficult to understand the Afghanistan, and Haiti) face challenges overcoming

All three PRSPs contain only limited health the population groups in greatest need are not reported. For example, the PRSP for Liberia per 1000 live births. However it did not break this variations in health outcomes between population data included in the PRSPs compared with the shown in Figure 2

Analysis

All three PRSPs give some aetiology of the health outcomes they provide data for, howeve evidence for household and community factors is limited. This is a potential problem considering an understanding of community factors like social and cultural norms, is imperative for the design of many interventions, especially community interventions parts of Afghanistan, there are normalised gender consent from her husbands in order to visit a health facily (15). This cultural practice is which

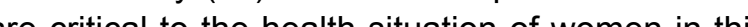
this.

The most commonly cited health system mitations are physical accessibility and availability of human resources, the importance of which is emphasised in the HNP Sourcebook. Howeve all three PRSPs lacked the disaggregated data groups and one cannot determine the burden of disease amongst the poor. A checklist of the recommendations made by the HNP Sourcebook is or education programs. For example, in some inequalities such that a women must require required to fully understand the barriers facing the poor

Providing pregnantwomen with professional supervision at the time of delivery is important to maternal health and yet all PRSPs approached this with inadequate analysis. All three PRSPs included the percentage of births attended by a trained health worker, which was below $50 \%$ in all cases. However, there is no explanation why this is low (16-18). Furthermore, none of the PRSPs give disaggregated data by income, wealth, or region. The Liberian DHS provides disaggregated data on the percentage of births attended by a trained women who give birth at home, in rural areas and in lower income groups (13). Once again, this dat was not included in Liberia's PRSP (17) hindering potential links that could be made between health sector.

In another example, pregnant women in Ragh, Afghanistan, are more likely to die during birth than women in Kabul (14). In addition, none of the women who died during pregnancy in Ragh had a health worker present during delivery (14). the health system is failing women in Ragh and additional information is needed to understand why. Maybe health facilities in Ragh are inaccessible to most women or perhaps pregnant women are being denied the opportunity to give birth in a health facility by their families. However, this information is missing in Afghanistan's PRSP and similar content is missing in the PRSPs of both Liberia and

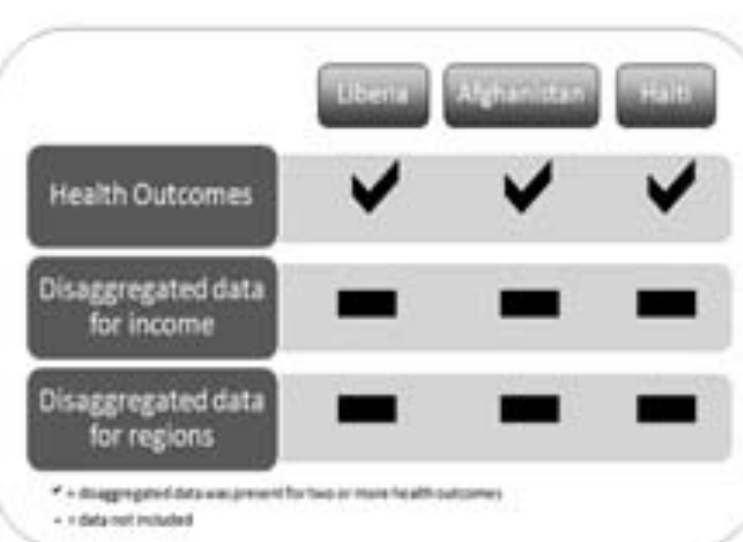

Figure 2: Data checklist for PRSPs vs the HNP Sourcebook health worker and showed this to be lower for Using this information, it could be suggested that
Haiti. All three PRSPs highlight maternal mortality is insufficiently analysed. A checklist of analyse included in the PRSPs has been given in Figure 3.

\section{Health Strategies}

Drawing links between the burden of strategies they propose is difficult given the lack of data and analysis. The problem worsens in the absence of disaggregated data, making hard to establish whether countries are targeting the poor or worse off population groups. All three Development Goals - specifically 4,5 and 6 (reducing maternal and child mortality and the (reving major diseases, respectively) and all aim to improve accessibility to and the quality f health sysems (16-18). Although none of PRSP expliclly (16-18). Alt with no the of cres by aiming to improve prim polth car, notably by aiming to improve primary health care and to crices (BPHS) $(16,17)$. Hait's PRSP dos sevices (BPHS) (16, 17). Halls PRSP does not mention implementing a BPHS (18). ABPHS could be of beneft in Haitt considering nearly half of the population lack access to basic healthcare and consequently, $80 \%$ turn to traditional medicine (19). All PRSPs are deficient in detailed links between analysis and health strategies. In all three countries, women in rural areas are less likely to receive medical attention during labour $(13,14,20)$. as a concern and yet the gravity of maternal healt disease within the countries and the health PRSPs align their objectives with the Millennium Accessibility to facilities amongst pregnant women

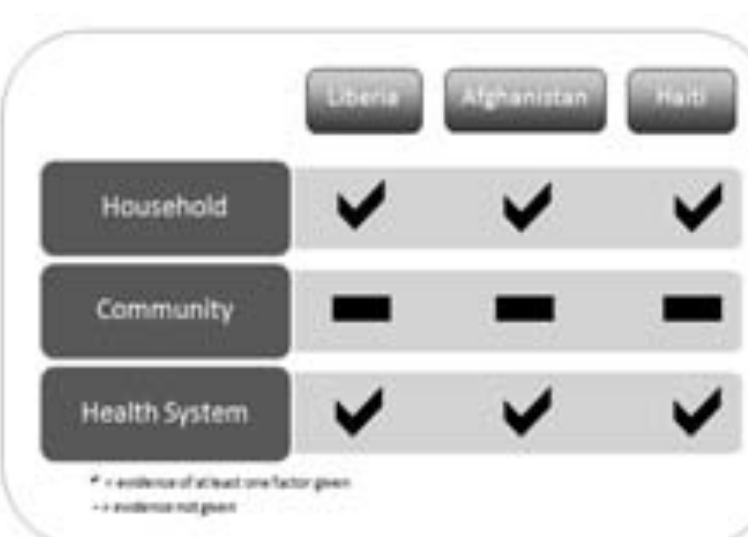

Figure 3: Analysis checklist for PRSPs vs the recommend 
PRSP (16) and Chatterjee (19) reports that some women in Haiti face a six hour or more journey to the nearest health facility. Because of such barriers, "many pregnant women die en route" (19). One approach to tackling the high maternal mortality in these countries could be to provide delivery care in women's homes. If performed by a skilled birth attendant and appropriate referral mechanisms are in place, this can achieve marked reductions in maternal mortality (21). If there were greater discussion within the PRSPs, that forged links between health outcomes and their aetiologies, a better understanding of the interventions required to improve the health of those most in need could be discerned. A checklist for health strategies is shown in Figure 4 .

\section{DISCUSSION}

This paper seeks to assess whether the health contents of three PRSPS (Liberia,Afghanistan and Haiti) are aligned with the suggestions made in the HNP Sourcebook, in relation to health data, health data analysis and health strategies. It was found that the three PRSPs contain inadequate health data (most notably disaggregated data) and insufficient analysis needed to portray the health situation in each country. Consequently, it is difficult to identify the health strategies which target the poor. This may be seen by donors as a lack of government capacity, which could threaten the aid the countries receive, with disastrous effects for the health sector. It is understandable, given the recent history and current situation of these three countries, that it may not be feasible to collect comprehensive data. However, in some instances, official data from surveys, for example, was available and was not included in the PRSPs, representing a serious missed opportunity. This suggests that governments are not paying due attention to health, which could be due to a number of reasons: governments may take a rushed approach when preparing PRSPs in order to quickly benefit from debt relief or theath may not be a high priority on the country's do health may no be a high prity a consider hevelh to bea prionty for PRSPs and

The feedback from the World Bank and IMF on the PRSPs of Liberia, Afghanistan, and Haiti does disaggregated health data and analysis of health

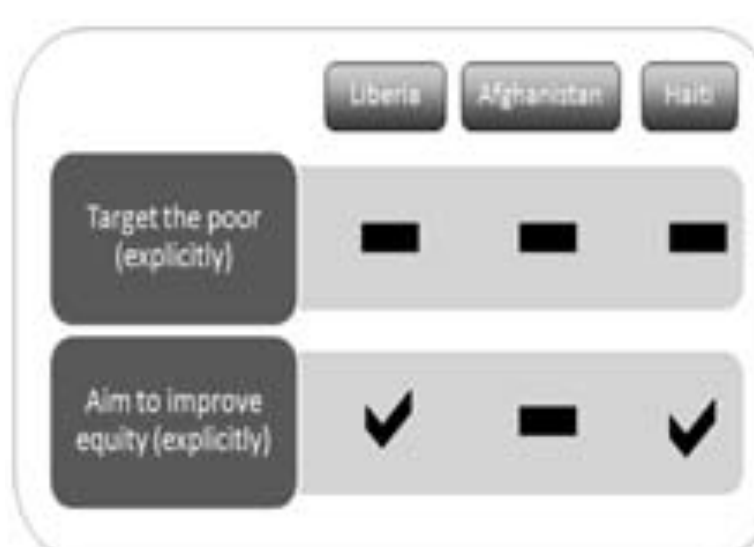

Figure 4: Health strategy checklist for PRSPs vs recommen-

outcomes or provide a critique of the health strategies proposed in the PRSPs (22-24). The World Bank and IMF have produced guidelines (25) for the staff responsible for writing the JSANs (referred to by the World Bank and IMF as 'the (taff'), which state that these should be "selective, and present a limited number of priority arective, trengthening". Therere it can be areas for treng assumed (he stafs did not consider the gaps in health that have been highighted in this paper from the three PRSPs to be high prionties. th is possible, then, that W World Bank and IMF actualy do not conside ealth to be a priority in PRSPs.

The HNP Sourcebook, along with PRSPs, does not recognise health as a human right. This further supports the hypothesis that health is no high on the IFIs agenda. Hammonds and Ooms (26) suggest that, in order to protect the right to health, LEDCs are obliged to raise sufficient funds for health. However, the World Bank and IMF recommend governments restrict the amount they spend on health in order to maintain macroeconomic stability. This can reduce the amount of money LEDCs ask for from donors and in turn reduces the amount of money they receive (26). As a result, the authors posit that the World Bank does no allow countries to raise enough money to uphold their obligations to protect the right to health. They argue that countries partial to the ICESCR - which make up over $75 \%$ of the votes on the Internation Development Association (IDA) board use their influence to compel the World should lign wir th align with the ICESCR and recognise health as a (27) go further in policies prescribed in PRSPs and that countries should reject reforms proposed by the World Bank and IMF th In addition, whilst analyses of health in PRSPs have been carried out, to my knowledge no such analysis or critique of the HNP Sourcebook exists. Thus, the guidelines provided by the World Bank and used by countries to prepare the health sections of PRSPs, have not been analysed in depth and accordingly revised.

Health and the right to health require further promotion in the PRSP process and the World Bank's agenda needs to be challenged. The WHO is responding to calls for assistance from LEDCs by developing a database to monitor health in PRSPs and by providing guidance to countries in the preparation of PRSPs (10). For this to be in the prepal a strong pers (10). For this to be (he (evels.

\section{CONCLUDING REMARKS}

The three PRSPs analysed do not provide adequate health information as recommended by the HNP Sourcebook. Consequently, none of the PRSPs clearly portray the health situation in their country and thus PRSPs are not affording due attention to health. It appears that health is a low priority for the World Bank and needs further promotion through the PRSP process so that health is recognzed as a human right and is subsequently placed firmly in the centre of the development agenda. PRSPs represent an opportunity for LEDCs to bring their people out of poverty. However, if health continues to receive insufficient attention, the situation for the world's poorest people unlikely improve.

\section{REFERENCES}

1. Gordon D. Poverty, Death \& Disease. In: Hillyard P, Pantazis C, Tombs S, Gordon D, editors. Beyond Criminology: Taking Harm Seriously. London: Pluto: 2004. p. 251-266.

2. Claeson M, Griffin $\mathrm{C}$, Johnston $\mathrm{T}$, et al. Health, Nutrition, and Population. In: Klugman J, editor. A Sourcebook For Poverty Reduction Strategies Volume 2 - Macroeconomic and Secloral Approaches. [ONIhe] Washinglon DC. World Bank, 2002. Available From. http.//siteresources.worldbank. chap18.pdf [Accessed 1 June 2010].
3. World Bank. Poverty Reduction Strategies. [Online] NO DATE; Available from: http://web.worldbank.org/WBSITE/ EXTERNAL/TOPICS/EXTPOVERTY/EXTPRS/0,,m nuPK:384207 pagePK:149018 piPK:149093 theSite PK:384201,00.html [Accessed 1 June 2010].

International Monetary Fund. Factsheet - Poverty Reduction Strategy Papers (PRSP). [Online] 2008; Available from: http://www.imf.org/external/np/exr/facts/ prsp.htm [Accessed 1 June 2010].

5. Walford V. Health in Poverty Reduction Strategy Papers (PRSPs). London: Department for Internationa Development Health Systems Resource Centre; 2002.

6. Wamala S, Kawachi I, Mpepo P. Poverty Reduction Strategy Papers: Bold New Approach to Poverty Eradication or Old Wine in New Bottles?. In: Kawachi I, Wamala S, editors. Globalization and Health. Oxford: Oxford University Press: 2007. p. 234-249.

Bretton Woods Project. Poverty Reduction Strateg Papers (PRSPs): A Rough Guide. London: Bretton Woods Project,2003.

8. World Development Movement. One size for all A study of IMF and World Bank Poverty Reduction Strategies. [Online] World Development Movement; 2005. Avialble From: http:/ www.wdm.org.uk/one-size-all-study-imf-and-world-bankpoverty-reduction-strategies [Accessed 1 June 2010]

9. Laterveer L, Niessen LW, Yazbeck AS. Pro-poor health policies in poverty reduction strategies. Health Policy Plan. 2002; 18(2): 138-145

10. Dodd R, Hinshelwood E, Harvey C. PRSPs: Their Significance for Health: second synthesis report. [Online] Geneva: Wolrd Health Organisation; 2004. Available From http://www.who.int/trade/prsps/en/ [Accessed 1 June 2010] 11. International Covenant on Economic, Social and Cultura Rights (ICESCR), 1966: article 12. Available From: http:/ www2.ohchr.org/english/law/cescr.htm [Accessed 1 Jun 2010].

12. World Bank. PRSP Sourcebook. [Online] NO DATE; Available from: http://go.worldbank.org/318LYLXO80 [Accessed 1 June 2010].

13. Liberia Institute of Statistics and Geo-Information Services (LISGIS), Ministry of Health and Social Welfare, National AIDS Control Program, Macro International Inc. Liberia Demographic and Health Survey 2007. Monrovia: Liberia: Deria Institute of Statistics and Geo-nformation Services (LISGIS) and Macro International Inc; 2008.

14. Bartlett L, Mawji S, Whitehead S, Crouse C, Dalil S, Ionete D, et al Where giving birth is a forecast of Dall S, lonete D, et al. Where giving bich is a forccast of death. maternal 2005; 365(9462): 864-870. 
15. Rockhopper TV. Fight For Life - Afghanistan. [Online] [video ecordingl 2005; Avalable From: http://www rockhopper. iv/ programmes/43 [Accessed 1 June 2010]

16. Islamic Republic of Afghanistan. Afghanistan National Development Strategy. [Online] Kabul: Afghansitan National Development Strategy Secretariat; 2005. Available From http://siteresources.worldbank.org/INTPRS1/Resources/ Afghanistan_PRSP(May2008).pdf [Accessed 1 June 2010]

17. Republic of Liberia. Poverty Reduction Strategy. [Online] Monrovia: Republic of Liberia; 2008. Available From: http./ siteresources.worldbank.org/INTPRS1/Resources/LiberiaPRSP(Jul2008).pdf [Accessed 1 June 2010].

18. Government of Haiti. Growth and Poverty Reduction Strategy Paper: Government of Haiti. [Online] Port-auPrince: Republic of Haiti; 2007. Available From: http:/ siteresources.worldbank.org/INTPRS1/Resources/HaitPRSP(march-2008).pdf [Accessed 1 June 2010].

19. Chatteriee P. Haiti's forgotten emergency. Lancet. 2008: 372(9639): 615-618.

20. Macro Inte [Onlinel 2009; Available from: htpp:/wwwstatcomplercom [Accessed 1 June 2010].

21. Koblinsky $M$ Call $O$, Heichelheim J Organish delivery care: Wat Work or safe molhenod? Bull Word Health Organ. 1999; 77(5): 339-406.

22. International Development Association, International Monetary Fund. Republic of Liberia Joint Staff Advisory Note on the Poverty Reduction Strategy Paper.[Online] International Development Association, International Monetary Fund; 2008 Available From: http://siteresources. PRSP\%28June24-2008\%29.pdf [Accessed 1 June 2010
23. International Development Association, Internationa Monetary Fund. Islamic Republic of Afghanistan Join Staff Advisory Note on the Poverty Reduction Strategy Paper. [Online] International Development Association, International Monetary Fund; 2008. Available From: http://siteresources.worldbank.org/INTPRS1/Resources/ Afghanistan_JSAN-PRSP(May15-2008).pdf [Accessed June 2010].

4. International Development Association, Internationa Monetary Fund. Haiti Joint Staff Advisory Note of the Poverty Reduction Strategy Paper. [Online] Internationa Development Association, International Monetary Fund; 2008. Available From: http://siteresources worldbank.org/INTPRS1/Resources/Haiti-JSANPRSP\%28Feb5-2008\%29.pdf [Accessed 1 June 2010].

25. International Monetary Fund, World Bank. Poverty Reduction Strategy Papers - Progress in Implementation. Annexe 2 - Guidelines for World Bank and IMF Staffs for Joint Staff Advisory Notes (JSAN) for Poverty Reduction Strategy Papers, [Onlinel 2001: Available From: htp Wur. [Accessed 1 June 2010]

26. Hammonds R, Ooms R. World Bank Policies and The Obligation of Its Members to Respect, Protect and Fulfil the Right to Health. Health Hum Rights. 2004;8(1): 26-60

27. Verheul E, Cooper G. Poverty Reduction Strategy Papers: What is at Stake for Health? Amsterdam: Wemos; 2001
ORIGINAL ARTICLE

\section{Salvage Resection for Isolated Local and/or Regional Failure of Head/Neck Cancer Following Definitive Concurrent Chemoradiotherapy} Case Series and Review of the Literature.

Patricia L. Kearney, John M. Watkins*, Keisuke Shirai, Amy E. Wahlquist, John A. Fortney, Elizabeth Garrett-Mayer M. Boyd Gillespie, Anand K. Sharma

\begin{abstract}
Background: Primary management of advanced head/neck cancers involves concurrent chemoradiotherapy. Subsequently, regional and local failures involves concurt chemolion are manadwe morbidity and disease control outcomes of surgical salvage in this setting. Methods: Retrospective analysis describes complications, survival, and patterns of failure af ter salvage resection of isolated local and/or regional failures of head/neck cancer following definitive concurrent chemoradiotherapy. Results. Sixteen patients were identified for inclusion: laryngectomy in 11 patients, oral cavity/oropharynx resection in 2 patients, and neck dissection alone in 4 patients. Ten patients required graft tissue reconstruction ( 6 pedicle and 4 free flap). Median post-operative hospitalization was 7 days (range 3-19), and 4 patients required hospital re-admission. At a median survivor follow-up of 15.8 months (range 4.3-34.9), 10 patients were alive ( 6 without evidence of disease). Seven patients experienced disease recurrence at a median 6.7 months (range $0-12.6$ ) following salvage resection (2 with isolated distant failures). Estimated 2-year local/regional control, freedom from failure, and overall survival were $58 \%, 39 \%$, and $58 \%$, respectively. Conclusions: Surgical salvage after primary definitive concurrent chemoradiotherapy is feasible with toxicity and outcomes similar to prior radiotherapy alone or sequential chemotherapy and radiation. Local andregional recurrence remains the predominant pattern of failure.
\end{abstract}

Keywords: Head and neck neoplasms, Combined modality therapy, Salvage therapy, Organ preservation therapy

\section{INTRODUCTION}

Locoregionally advanced head and neck cancers are optimally treated with definitive concurrent chemoradiotherapy or surgical resection with or without chemo"To whom correspondence should be addressed: Bismarck Cancer Center, 500 North 8th St, Bismarck, ND 58501; Office: $800-248-55$ herapy (1). Despite aggressive local treatment herapy (1). Despite aggressive local treatmen locoregional recurrence within $3-5$ years, representing $50-67 \%$ of all recurrences (1-3). In patients who experience disease recurrence within a previously irradiated field, aggressive salvage surgical resection is the preferred intervention (4). Previously reported series of surgical salvage have generally included patients treated with suboptimal primary 